\title{
Parental inheritance and perinatal tobacco smoke exposure increase the gender-dependent risk of physician diagnosed asthma at preschool age
}

\author{
Chih-Chiang Wu ${ }^{1,2,3}$, Te-Yao Hsu ${ }^{4 *}$, Ho-Chang Kuo ${ }^{5}$, Chia-Yu Ou ${ }^{4}$, Jen-Chieh Chang ${ }^{6,7}$, Chieh-An Liü, \\ Chih-Lu Wang ${ }^{8}$, Hua Chuang ${ }^{7}$, Hsiu-Mei Liang ${ }^{4}$, Kuender D Yang ${ }^{2,3,9^{*}}$ \\ From Canadian Society of Allergy and Clinical Immunology Annual Scientific Meeting 2013 \\ Toronto, Canada. 3-6 October 2013
}

\section{Background}

Genetic inheritance and perinatal tobacco smoke exposure (TSE) have been proven to be critical for the development of childhood allergic diseases [1,2]. This study investigated the interactive roles of parental allergic histories and TSE on the development of childhood asthma at 6 years old.

\section{Methods}

A birth cohort in southern Taiwan was studied. Information about parental allergic histories, gender, prematurity, TSE, and childhood allergic disease ever diagnosed by a physician were acquired from questionnaire during follow up. Children were asked to follow up at 6 years of age for allergic questionnaire and sensitization examination (CAP system).

\section{Results}

In this cohort study, 748 of the children with complete data were analyzed. 217 (29\%) of children had positive parental allergic history, 191 (25.5\%) of children had TSE history, and 186 (24.9\%) of children had been diagnosed as asthma by a physician in the first 6 years of life. In a regression analysis, physician diagnosed asthma ever in the first 6 years of life were significantly associated with male gender (OR: 1.941, 95\% CI: 1.371-2.748, $\mathrm{p}<0.001$ ), either parent with allergic diseases (OR: $1.548,95 \% \mathrm{CI}$ : 1.047-2.288, $\mathrm{p}=0.028$ ), and TSE (OR: $1.504,95 \% \mathrm{CI}$ : 1.038-2.179, $\mathrm{p}=0.031)$, but not significantly associated with preterm ( $\mathrm{p}=0.801)$. TSE with more than 20 cigarettes per day made children significantly higher risky to have physician-diagnosed-asthma than those with smoke exposure less than 20 cigarettes per day or those without smoke exposure (35\%, $25 \%$ and $22.7 \%$ respectively, $\mathrm{p}=0.003)$. TSE was not related to physician diagnosed rhinitis, dermatitis or allergic sensitization by 6 years of age ( $>0.5)$. Besides, TSE and parental allergic history had synergistic influence on the physician diagnosed asthma ever in the 6 years of life. This synergistic influence was significant in girls, rather than in boys (Table 1 ).

\section{Conclusions}

In the prospective cohort study, we found that male gender, parental allergic history, and TSE were significantly associated with physician diagnosed asthma by 6 years of age. TSE and parental allergic history had synergistic effect on the physician diagnosed asthma by 6 years of age. This synergistic influence was significant in girls, rather than boys.

\footnotetext{
* Correspondence: phachang@gmail.com

${ }^{2}$ Department of Medical Research, Show Chwan Health Care System in Chang Bing, Changhua, Taiwan

${ }^{4}$ Department of Obstetrics and Gynecology, Kaohsiung Chang Gung Memorial Hospital, Taiwan and Chang Gung University College of Medicine, Kaohsiung, Taiwan

Full list of author information is available at the end of the article
} 
Table 1 TSE and parental allergic history had synergistic influence on the physician diagnosed asthma ever in the 6 years of life. This synergistic influence was significant in girls, rather than boys

\begin{tabular}{|c|c|c|c|c|c|}
\hline All & physician & asthma & OR & $95 \% \mathrm{Cl}$ & $\mathrm{p}$ (compared with A) \\
\hline parent allergic disorder -, TSE- (A) & $30 / 161$ & $18.60 \%$ & 1 & & \\
\hline parent allergic disorder +, TSE- & $97 / 396$ & $24.00 \%$ & 1.417 & $0.896-2.240$ & 0.135 \\
\hline parent allergic disorder -, TSE+ & $13 / 56$ & $23.20 \%$ & 1.32 & $0.632-2.757$ & 0.459 \\
\hline parent allergic disorder + , TSE + & $46 / 135$ & $34.10 \%$ & 2.257 & $1.325-3.846$ & 0.002 \\
\hline Girls & & & & ompared with & \\
\hline parent allergic disorder -, TSE- (A1) & $4 / 72$ & $5.60 \%$ & 1 & & \\
\hline parent allergic disorder +, TSE- & $38 / 196$ & $19.40 \%$ & 4.089 & $1.404-11.905$ & 0.006 \\
\hline parent allergic disorder -, TSE+ & $3 / 23$ & $13.00 \%$ & 2.55 & $0.526-12.353$ & 0.231 \\
\hline parent allergic disorder + , TSE + & 20/61 & $32.80 \%$ & 8.293 & 2.649-25.964 & $<0.001$ \\
\hline Boys & & & & compared with & \\
\hline parent allergic disorder -, TSE- (A2) & $28 / 89$ & $29.20 \%$ & 1 & & \\
\hline parent allergic disorder + , TSE- & $59 / 200$ & $29.50 \%$ & 1.014 & $0.586-1.755$ & 0.961 \\
\hline parent allergic disorder -, TSE+ & $10 / 33$ & $30.30 \%$ & 1.054 & $0.441-2.519$ & 0.907 \\
\hline parent allergic disorder + , TSE + & $26 / 74$ & $35.10 \%$ & 1.313 & $0.678-2.541$ & 0.419 \\
\hline
\end{tabular}

\section{Authors' details}

'Department of Pediatrics, Show Chwan Memorial Hospital, ChangHua, Taiwan. ${ }^{2}$ Department of Medical Research, Show Chwan Health Care System in Chang Bing, Changhua, Taiwan. ${ }^{3}$ Institute of Clinical Medicine, National Yang-Ming University, Taiwan. ${ }^{4}$ Department of Obstetrics and Gynecology, Kaohsiung Chang Gung Memorial Hospital, Taiwan and Chang Gung University College of Medicine, Kaohsiung, Taiwan. ${ }^{5}$ Department of Pediatrics, Kaohsiung Chang Gung Memorial Hospital and Chang Gung University College of Medicine, Kaohsiung, Taiwan. ${ }^{6}$ Division of Dermatology, Department of Medicine, McGill University Health Centre, Canadalnstitute of Biomedical Sciences, National Sun Yat-Sen University, Kaohsiung, Taiwan. ${ }^{7}$ Genomic and Proteomic Core Laboratory, Department of Medical Research, Kaohsiung Chang Gung Memorial Hospital and Chang Gung University College of Medicine, Kaohsiung, Taiwan. ${ }^{8}$ Department of Pediatrics, Po-Jen Hospital, Kaohsiung, Taiwan. ${ }^{9}$ Department of Pediatrics, Po-Jen Hospital, Kaohsiung, Taiwan.

Published: 3 March 2014

\section{Submit your next manuscript to BioMed Central} and take full advantage of:

- Convenient online submission

- Thorough peer review

- No space constraints or color figure charges

- Immediate publication on acceptance

- Inclusion in PubMed, CAS, Scopus and Google Scholar

- Research which is freely available for redistribution

Submit your manuscript at www.biomedcentral.com/submit
C Biomed Central 